\title{
Road Pricing Effect on the Emission of Traffic Pollutants, A Case Study in Tehran
}

\author{
Mansour Hadji Hosseinlou ${ }^{\mathrm{a}}$, Abbas Zolfaghari ${ }^{\mathrm{b}^{*}}$, Mahdi Yazdanpanah ${ }^{\mathrm{c}}$ \\ ${ }^{a}$ Assistant professor, Civil Engineering Department, K.N. Toosi University of Technology, Tehran, Iran \\ ${ }^{b}$ MSc., Civil Engineering Department, K.N. Toosi University of Technology, Tehran, Iran \\ ${ }^{c}$ Ph.D. Candidate, Civil Engineering Department, K. N. Toosi University of Technology, Tehran, Iran
}

Received 5 April 2016; Accepted 23 July 2016

\begin{abstract}
Road pricing is one of the main purposes of traffic management policies in order to reduce personal car use. Understanding the behaviour of drivers under the impact of the road pricing policy, can assist transportation planners in making better and more efficient decisions. This research aims at investigating the reactions of private car users to road pricing using stated preference (SP) method on the one hand, and on the other hand, studies the road pricing effect on traffic flow and pollutants. To this aim, the acceptance rate of pricing, which is obtained from modelling of survey data, as well as real traffic flow data in Shahid Hemmat Highway in Tehran, Iran, are applied as the simulation software input. Based on the results of this research, at the lowest price $\left(\mathrm{TN}^{1} 1000\right)$, the contribution of toll acceptance is equal to 64.91 percent. The fuel consumption rate at this price decreases to $49.91 \%$ and the emission rate of $\mathrm{CO}_{2}, \mathrm{NOx}$, particulate matter (PM) and volatile organic compounds (VOCs) pollutants decrease to $56.82 \%, 49.46 \%, 36.8 \%$ and $63.17 \%$, respectively. At the highest price (TN10000), toll acceptability, fuel consumption, $\mathrm{CO}_{2}, \mathrm{NOx}, \mathrm{PM}$ and VOC emission rates decrease to $5.47 \%, 3.57 \%, 3.98 \%, 2.85 \%, 1.22 \%$ and $4.86 \%$, respectively.
\end{abstract}

Keywords: Road Pricing; Stated Preference Method; Binary Logit Model; Traffic Pollutants; Willingness-To-Pay.

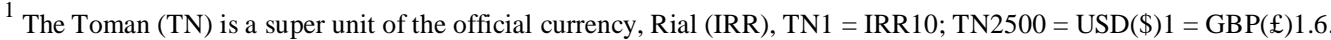

\section{Introduction}

Nowadays, traffic congestion and subsequent travel delays and air pollution have become significant problems for most urban communities. Along with the rapid development of transportation, the emissions from motor vehicles have become a major source of air pollution. In EU countries, road transportation contributed to $39.4 \%$ of NOx (nitrogen oxide), $36.4 \%$ of $\mathrm{CO}$ (carbon monoxide) and $17.9 \%$ of NMVOC (non-methane volatile organic compounds) emissions in 2006 [1]. In Australia, passenger cars account for 85 percent of all road activity petrol consumption, and contribute to eight percent of national greenhouse gas emissions [2]. It is estimated that traffic congestion in Australia resulted in AU $\$ 9.41$ billion of avoidable social costs in 2005 (including extra time costs (private and business), extra vehicle operating costs and extra emission costs), increasing to AU $\$ 20.4$ billion by 2020 [3].

In the USA, the Texas Transportation Institute reports, in its 2012 Urban Mobility update [4] that congestion costs (in constant 2011 dollars) continue to rise from US $\$ 24$ billion in 1982 to US $\$ 121$ billion in 2011 . This is associated with 2.9 billion gallons of wasted fuel (enough to fill four New Orleans Superdomes), $\$ 121$ billion of delay and fuel cost (the negative effect of uncertain or longer delivery times, missed meetings, business relocations and other congestion-related effects are not included), 56 billion pounds of additional carbon dioxide $\left(\mathrm{CO}_{2}\right)$ greenhouse gas released into the atmosphere during urban congested conditions, and the cost to the average commuter was $\$ 818$ in 2011 compared to an inflation-adjusted \$342 in 1982.

\footnotetext{
* Corresponding author: azolfaghari@mail.kntu.ac.ir
} 
Because of limitations on expanding transportation networks, policymakers have attempted to reduce car usage by proposing transportation demand management (TDM) policies over the past several decades. TDM is a general term for strategies that result in more efficient use of transportation resources [5]. One of the most important strategies used for demand management is the use of road pricing. The initial idea of road pricing was proposed by Pigou [6], who gave the optimal charges on a congested road.

The purpose of this study is investigating the reactions of private car users to road pricing and also estimating the emission rate of traffic pollutants before and after adopting the policy of road pricing.

\subsection{Backgrounds on Road Pricing}

At a practical level, several studies and overviews exist that evaluate the effects of pricing on traffic congestion and pollution.

The longest standing urban road-pricing scheme is that of Singapore which originally introduced an area licensing scheme in 1975 and replaced it in 1999 by an electronic road pricing scheme [7], followed by the Norwegian cities during years 1986-2001 (Bergen, Oslo, Trondheim, Kristiansand and Stavanger) [8]. The aim of road pricing in Singapore is to alleviate huge congestion and pollution problems. Implementation of pricing scheme in Singapore, reduced cars volume by 45 percent in city center [9]. Two European cities, Rome and London, are known to suffer from severe congestion and environmental problems. In Rome, there has for long been attempts to introduce various measures to restrict access to the historical city center by private cars, of which the introduction of pricing is just the latest measure [10], as well as Starting from January 2008 Milan implemented a charging scheme to enter an $8 \mathrm{~km} 2$ area in the city center in order to improve the quality of the urban environment [11].

The most important example in Europe is now London with its introduction of urban road pricing in central London on 17 February 2003. The London congestion charging scheme operates in a small area of Central London that covers only 21 square kilometers. The main results of London congestion charging scheme are as follows:

Traffic flow in the charging zone and period has been reduced by about $15 \%$. Car movements into the zone have been reduced by $30 \%$ with taxi, bus and coach movements all increasing by $20 \%$. In July 2005 the basic charge was raised from $£ 5$ (\$7.8) to $£ 8(\$ 12.5)$ per day. It increased to $£ 10(\$ 15.6)$ in 2011 and $£ 11.5(\$ 18)$ in $2014[12,13]$

The charging system in Stockholm consisted of a cordon around the center of the city of Stockholm, with a charge imposed 6.30-18.30 weekdays. The charge was 20 SEK (\$2.72) during peak hours and 10 SEK (\$1.36) during offpeak. The decline in traffic as a consequence of congestion charging is estimated to reduce traffic flow by $16 \%$ and the emissions between $10 \%$ and $14 \%$ [14].

Urban road charging schemes can cover the road network as a whole or can only be restricted to an individual road or on a certain stretch of a single road. Examples of the latter types of applications are in the U.S. and Canada. On the State Route 91 in Riverside County in California and on Highway 407 north of Toronto in Canada, the price system is time-dependent pricing according to a predictable schedule [10].

There are also some studies from theoretical point of view.

Verhoef et al.'s study [15] is among the earliest studies that investigated congestion pricing acceptability. Verhoef et al. sampled car drivers in the Dutch Randstad area and asked them to indicate their opinions on congestion pricing (e.g., "'good idea", “'bad idea”, “"no opinion”).

Schuitema et al. [16] examined the differences between respondents' belief about the consequences of the congestion charge before (December 2005) and after (August 2006) the charge was implemented in Stockholm. To this aim, some questionnaires were distributed and gathered. The comparison of the results obtained before and after pricing showed that the acceptance of congestion charge after administering the scheme was more than that before using it. Respondents believed congestion, parking problems and pollution decreased more than they believed before the charge was implemented. They concluded that the acceptance of the congestion charge in Stockholm is higher than its acceptability, because people had more positive and less negative beliefs about the consequences of the charge after the trial.

Azari et al. [17] indicated that congestion pricing is more efficient than parking pricing to change travel mode choice. In other words, drivers are highly sensitive to congestion charge and are more willing to pay for parking fee. Azari et al. [18] investigated the demand for workers and non-workers trip using stated preference data and multinomial logit. They concluded that workers have a greater willingness to pay for parking and cordon pricing than non-workers. Furthermore, workers are more likely to shift mode in response to changes in travel time. This means that the effect of reduced travel time is more effective than increased travel cost in encouraging workers to shift mode.

Yusuf et al. [19] studied an explanatory model of willingness-to-pay tolls based on four factors. They found that willingness-to-pay is primarily driven and motivated by self-interest, through a balancing of benefit to cost relative to 
individual income and frequency of use. In addition, concern for the community also contributes to willingness-to-pay tolls. The individual's perception of government's trustworthiness, a reflection of political and environmental beliefs, also influences the extent to which an individual is willing to pay tolls.

\section{Research Methodology}

The stated preference method has been applied for data gathering in this study. To gather information regarding travelers' revealed preferences (RPs) or existing decisions, researchers usually measure real travel behavior. However, in order to examine the supposed choice scenarios, information regarding stated preferences (SPs) is collected [20]. Stated-preference techniques, named as the alternative-specific discrete choice experiment (DCE), were originally developed to conduct marketing research in the early 1970s [21]. Stated preference techniques are based on what people say rather than what they do. These methods have been developed to overcome the drawbacks of revealedpreference methods [22]. The SP experiment considers fewer attributes, but it is more flexible than the revealed preference experiment [23].

Due to the nature of the response variable, a discrete choice random-utility model is used to modeling the respondents' choice.

In random utility theory, it is assumed that the utility function of the alternative $i$ for individual $\mathrm{n}$ is expressed as follow:

$U_{\text {in }}=V_{\text {in }}+\varepsilon_{\text {in }}$

Where $V_{i n}$ is a systematic term and $\varepsilon_{i n}$ is a random term that includes effects that are not observed by the modeller. The systematic component $V_{\text {in }}$ depends on the sum of decision attributes related to the alternatives $i$ and socioeconomic attributes related to the individual $n$. The error term is assumed to have a zero mean and varies according a certain type of probability distribution function [24].

This paper uses Binary Logit model for the estimation of drivers' choice. The utility of each alternative depends on the attributes of the alternatives interacted perhaps with the attributes of the person, which gives this expression for the probability:

$P_{i}=\frac{e^{V_{\text {in }}}}{1+e^{V_{\text {in }}}}$

In which $P_{i}$ is the probability of travelers choosing to pay charge.

In order to obtain the amount of traffic pollutants when using the pricing policy, Aimsun software was employed in this study. Aimsun is one of the most powerful types of traffic software that can be used for both urban and non-urban traffic. This software is used for transportation network modeling, simulation, planning and traffic network management and also is able to estimate the vehicular emissions in different condition.

\section{Survey}

\subsection{Data Collection}

Data collection through questionnaire is one of the most common methods used to get information about the demand sector. Such information can be helpful in the process of demand analysis for the purpose of better understanding the influential factors and the selecting individuals for model construction in the transportation area. To this aim, the data related to people that travelled through Shahid Hemmat Highway, which is one of the most travelled routes in Tehran, during morning and/or evening rush hours were collected.

With a current population of over 8.6 million, Tehran, the capital and the first largest city of Iran, generates about 17.6 million trips per day [25].

Shahid Hemmat Highway in Tehran is an important east-west path with an approximate length of $18 \mathrm{Km}$. This highway suffers from heavy traffic during morning and evening rush hours. To reduce traffic in this highway, different plans have been proposed, most of which are related to the change in traffic planning [26].

Figure 1. Shows the Shahid Hemmat Highway in Tehran and also the volume of passenger car equivalent in morning rush. 


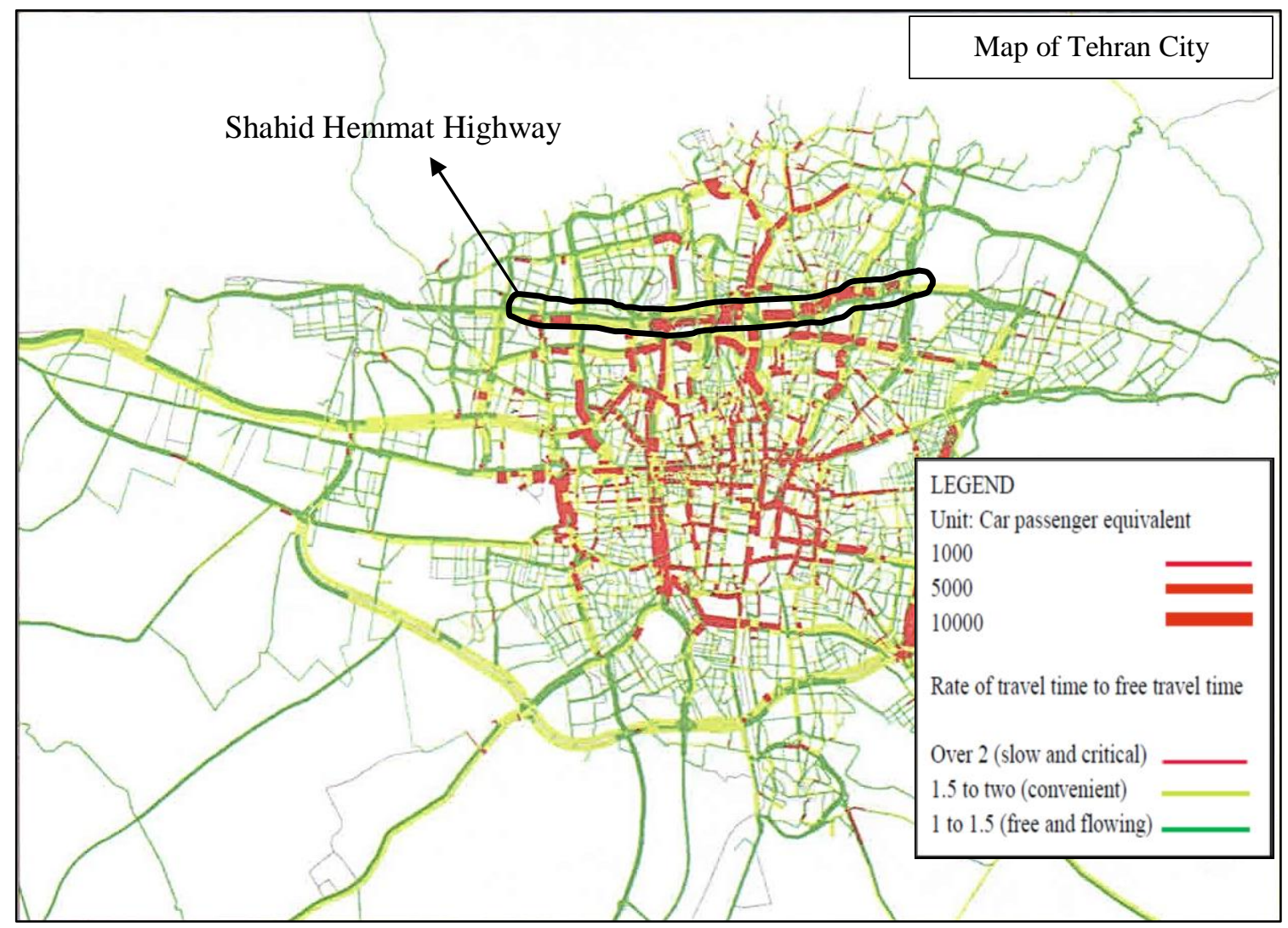

Figure 1. The volume of passenger car equivalent in morning rush [27]

Accordingly, the target group in this study consisted of all individuals who pass this highway during rush hours by their own cars. In the process of data collection, socio-economic features, trip plan (the alternative considered) and trip features were taken in to account.

In designing the questionnaire of this research, by offering different price levels for entrance into the highway, the willingness-to-pay of individuals was investigated. The data needed for the questionnaire consisted of three independent collections of information:

- Information related to socio-economic features

- Information related to the trip and transportation mode

- Information related to people's response to policies and changes considered in this study (stated preferences)

The first class of information included such attributes as gender, age, marital status, number of family members, occupation, residential place and characteristics of car or cars used. Such attributes, after determining correlation and degree of effectiveness, can be considered as an independent variable for utility models.

The second class of information was collected in order to identify the trip chain of the person questioned during a working day in the middle of the week. The selection of a working day was done by considering the fact that obligatory trips such as business trips or those for education caused the highest traffic. The questions raised in this part included the main purpose of trip, origin and destination, travel time, car occupants and the entrance time in the area under study.

The third class of information included people's views on coping with pricing scenarios.

In the process of gathering data required in this study, limitations due to time and budget constraints and also executive limitations were present.

Face-to-face interviews were conducted with drivers travelling through Shahid Hemmat expressway for 12 days. Each individual interview lasted 10-15 minutes. Data collection was done in the morning early hours, which can be regarded as the beginning of trips, and evening late hours, when there were more return trips. 250 people agreed to face-to-face interviews among more than 300 people approached. The collected data was cleaned and errors removed, resulting in 219 valid samples, of which yielded a total of 1095 choice observations.

For pricing, five different levels were considered, a lower limit (TN1000), an upper limit (TN10000) and three middle limits (TN3000, 5000 and 7500). Pricing at the lower limit was done in such a way that most people with 
private cars could pay for it. Pricing at the upper limit, on the other hand, was done in such a way that people would have almost no willingness-to-pay for it. Also, this pricing was considered for rush hours (6:30-10 and 16-19).

Descriptive statistics of collected data are presented in Table 1.

Table 1. Descriptive statistics of respondents

\begin{tabular}{|c|c|c|c|c|c|}
\hline Characteristic & Category & Percent & Characteristic & Category & Percent \\
\hline \multirow{4}{*}{$\begin{array}{l}\text { Number of car } \\
\text { occupants }\end{array}$} & 1 & 64.4 & \multirow{2}{*}{ Gender } & Female & 16.4 \\
\hline & 2 & 21.9 & & Male & 83.6 \\
\hline & 3 & 11 & \multirow{5}{*}{ Trip purpose } & Work & 45.2 \\
\hline & 4,5 & 2.8 & & Shopping & 4.1 \\
\hline \multirow{3}{*}{$\begin{array}{l}\text { Number of vehicles } \\
\text { in family possession }\end{array}$} & 1 & 47.9 & & Train & 19.2 \\
\hline & 2 & 45.2 & & Personal affairs & 16.4 \\
\hline & 3 and more & 6.9 & & Entertainment & 15.1 \\
\hline \multirow{4}{*}{ Age (year) } & $18-30$ & 46.6 & \multirow{4}{*}{ education } & Diploma and less & 27.4 \\
\hline & $30-39$ & 27.4 & & Undergraduate & 13.7 \\
\hline & $40-49$ & 12.3 & & graduate & 35.6 \\
\hline & 50 and more & 13.7 & & Postgraduate & 12.3 \\
\hline
\end{tabular}

\subsection{Data Required for Aimsun Simulator}

One of the effective parameters in the road traffic emission is the volume of vehicles in the paths studied. To this aim, the statistics related to the volume of vehicles were obtained from Tehran Traffic Control Co. in the form of 15 minute intervals for Shahid Hemmat's entrance and exit ramps.

The vehicle emissions data was collected by referring to the information made available by Iran Standard \& Quality Inspection Co. and Research \& testing of vehicle emissions center. Also, in order to match the simulated models with the actual existing situations, the portion of the different vehicles numbered in Tehran were obtained from traffic police.

\section{Modeling}

In the modeling process performed in this study, it was attempted to use the most possible complete definitions of variables to process the models and the different types of variables required; and the impact of them has been considered in the model. Exploratory variables in this study were directly obtained from the questions in the questionnaire or when needed, they were defined as newly made variables.

Like other models, the process of making the discrete choice models included determining values of model parameters and investigating the significance of these parameters and their coefficients.

It should be noted that based on different states resulting from the definition of each variable, different states can be created for the positioning of the variables in the model. In the models made in this study, it has been attempted to investigate all states and choose the best one as the supreme model.

Finally, after making and analyzing a large number of estimations, the result of binary logit model showing the willingness-to-pay for private car users passing Shahid Hemmat Highway was developed as shown in Table 2. In this model, the alternative of 'private car with accepting to pay the price' has been chosen as the base 'alternative with zero utility'. Therefore, variables with positive coefficient in the model show more utility resulting from choosing the private cars by accepting to pay the price and in comparison to other alternatives, variables with negative coefficient mean less utility. 
Table 2. Results of binary logit model - Private car users' willingness to pay

\begin{tabular}{ccc|ccc}
\hline Attribute & $\begin{array}{c}\text { Parameter } \\
\text { estimate }\end{array}$ & t-value & Attribute & $\begin{array}{c}\text { Parameter } \\
\text { estimate }\end{array}$ & t-value \\
\hline Constant & -1.407 & -2.27 & Trip purpose (shopping) & 2.444 & $\mathbf{4 . 9 4}$ \\
Gender(male) & 1.669 & 5.47 & Trip purpose (train) & 0.960 & $\mathbf{2 . 8 8}$ \\
Age & -0.0206 & -2.09 & Trip purpose (work) & 0.954 & $\mathbf{2 . 9 7}$ \\
Education (undergraduate) & 0.975 & 3.52 & Trip purpose (entertainment) & 0.557 & $\mathbf{1 . 7 4}$ \\
Education (postgraduate) & 0.161 & 0.52 & Car occupant & 0.145 & $\mathbf{1 . 3 8}$ \\
Education (Ph.D.) & -0.205 & -0.56 & Travel time & 0.0193 & $\mathbf{4 . 6 2}$ \\
Car price (less than TN20 million) & -1.030 & -3.88 & Frequency per month & -0.0415 & $\mathbf{- 2 . 4 2}$ \\
Car price (between TN20 \& 40 million) & 0.057 & 0.28 & Road charge & -0.443 & $\mathbf{- 1 4 . 8 0}$ \\
\cline { 4 - 6 } Car price (more than TN40 million) & 0.106 & 0.38 & $\mathbf{\rho}_{\mathbf{c}}^{\mathbf{2}}=\mathbf{0 . 3 1 6}, \mathbf{\rho}^{\mathbf{2}}=\mathbf{0 . 4 0 1}$ & \\
\hline
\end{tabular}

\subsection{Interpretation of Model Results}

The most important results obtained from modeling are as follows:

- With the increase in age, the willingness-to-pay is decreased. Also, Men are more inclined to pay than women.

- People with more expensive cars are more willing to pay and use their own cars. Since people who own more expensive cars, generally have a greater ability to pay, they are more willing to pay and use private car.

- With the increase in the level of education, the willingness-to-pay is decreased. People with shopping and business purposes are more willing to pay.

- With the increase in the number of car occupants and travel time, the willingness-to-pay is enhanced. Since with increasing the number of passengers, the ratio of cost to the number of passengers is reduced, so the willingness to pay also increases.

- The increase in the number of times people used the highway during the month leads to the reduction of willingness-to-pay. With increasing the frequency of passing the highway, the number of payments increases, therefore fewer users tend to pay.

- The most significant and sensitive effect is related to toll such that with the increase in it, the willingness-topay is decreased dramatically.

Fitness of good indexes in logit model are the $\rho^{2}$ and $\rho_{c}^{2}$ statistic. The obtained values for $\rho^{2}$ and $\rho_{c}^{2}$ in this model are equal to 0.401 and 0.316 , respectively.

Figure 2. shows the acceptance rate of road pricing for different prices according to the obtained model. About 65 percent of individuals are willing to pay by imposing TN1000 toll, while only about 5.5 percent are willing to pay by imposing TN10000 toll.

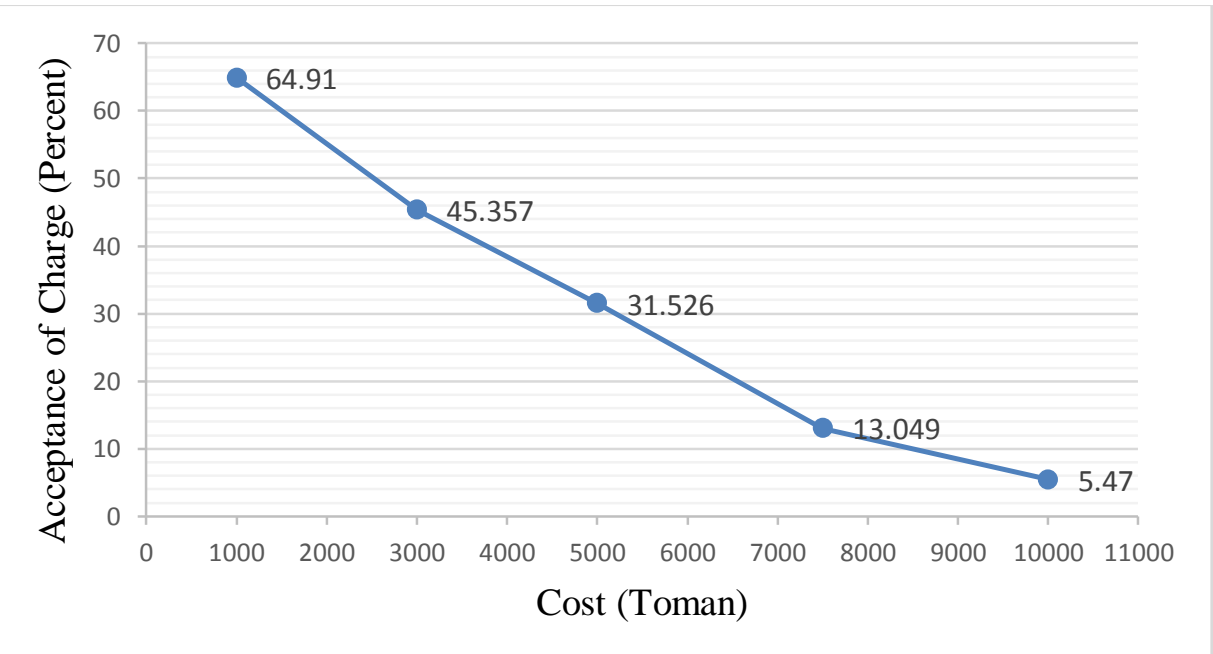

Figure 2. Acceptance rate of pricing for different levels of price 


\section{Traffic Analysis Results}

In order to analyze the traffic flow when using the pricing policy, Aimsun software was employed in this study. Regarding this, different levels of traffic demands for different prices were entered in to the software and simulation was done separately. The results obtained by analyzing the effect of traffic flow on the parameters of delay time, number of stops, total travel time and total distance travelled are shown in Figure 3. As can be seen, by imposing the toll, traffic parameters improve. As the value of toll increases, personal car usage is reduced.

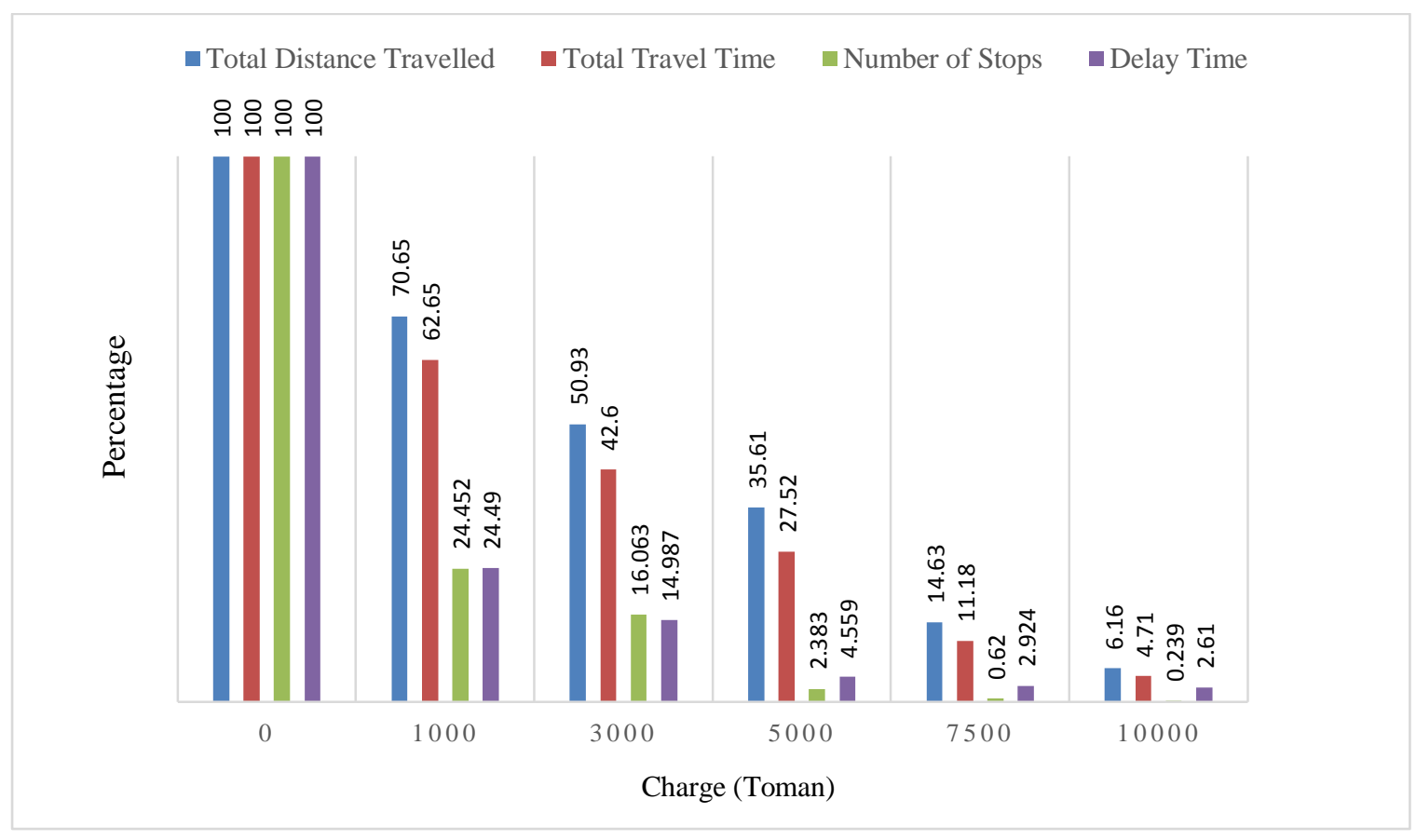

Figure 3. Effect of road pricing on traffic flow parameters

\section{The Emission Rate of the Pollutants}

In order to obtain the amount of traffic pollutants when using the pricing policy, Aimsun software was employed. Regarding this, different levels of traffic demands for different prices were entered in to the software and simulation was done separately. The results of emission of pollutants are shown in Figure 4.

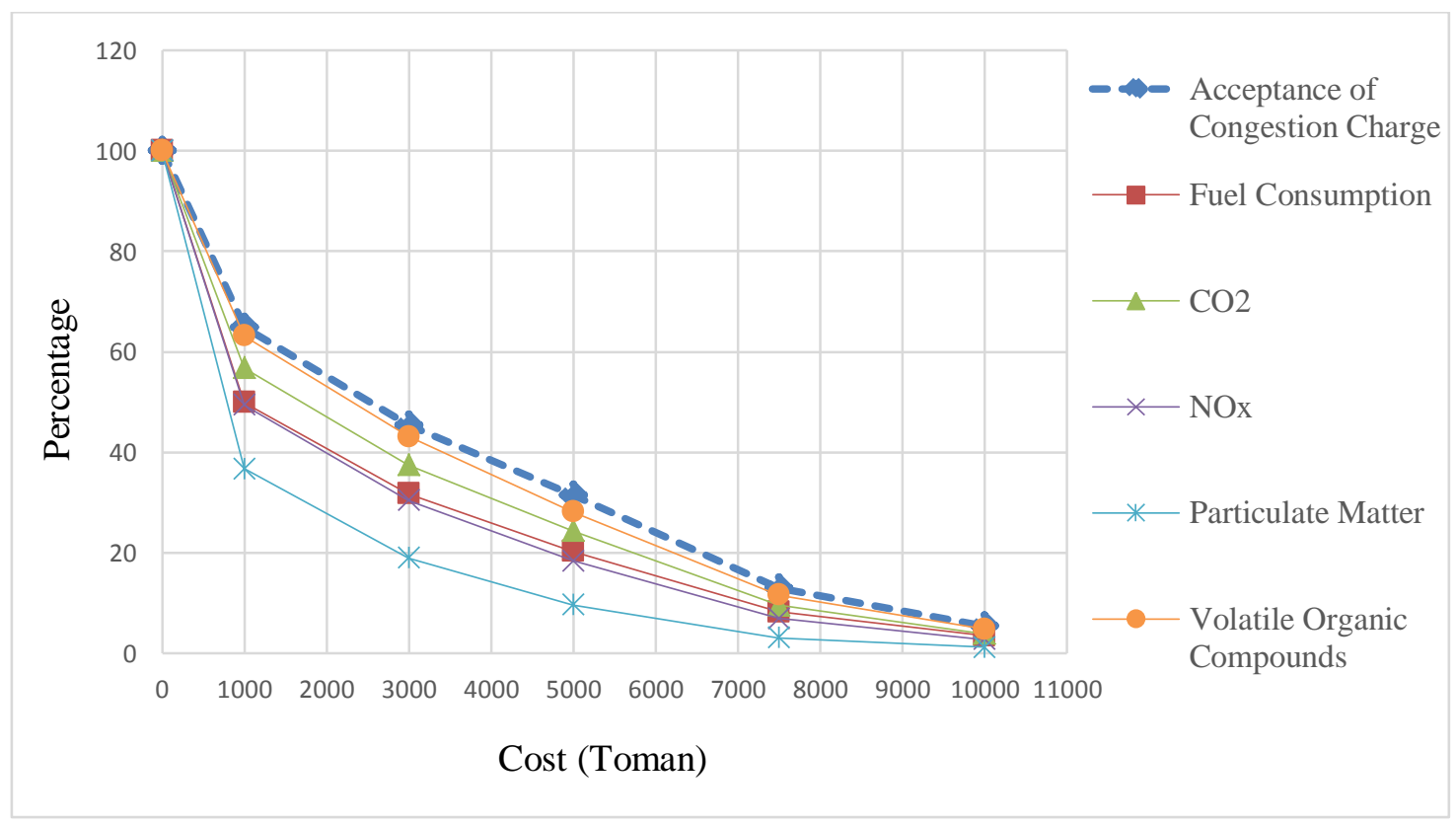

Figure 4. The contribution of emission of pollutants and fuel consumption in comparison to the reduction of demand with different passage tolls 
As can be seen in Figure 4, all pollutants and also, fuel consumption show more reduction in comparison to the decrease in the number of private cars, with the same charge. The biggest reduction is related to particulate matter. After that, fuel consumption and NOx pollutant represent the highest reduction. $\mathrm{CO}_{2}$ and finally, VOC show the least reduction.

All pollutants and also, fuel consumption, after a considerable decrease in the price of TN1000, follow a decreasing trend up to the price of TN3000. The highest difference in the pollutant emission, relative to the decrease in the number of private cars, occurred at the price of TN3000. In other words, the highest efficiency is at the price of TN3000. From this price on, this difference follows a decreasing trend such that at the price of TN10000, the difference in the reduction of emission of pollutants and decrease in the number of private cars reaches to its least rate.

Table 3. shows the contribution of emission of pollutants and fuel consumption in different passage tolls. As can be seen, at the price of TN1000, the contribution of toll acceptance is equal to 64.91 percent. The fuel consumption rate at this price decreases to $49.91 \%$ and the emission rate of $\mathrm{CO}_{2}, \mathrm{NOx}$, particulate matter (PM) and volatile organic compounds (VOCs) pollutants decrease to $56.82 \%, 49.46 \%, 36.8 \%$ and $63.17 \%$, respectively.

At the highest price -TN10000-, toll acceptability, fuel consumption, $\mathrm{CO}_{2}, \mathrm{NOx}, \mathrm{PM}$ and VOC emission rates decrease to $5.47 \%, 3.57 \%, 3.98 \%, 2.85 \%, 1.22 \%$ and $4.86 \%$, respectively. Other values can be seen in Table 3 .

Table 3. Contribution of emission of pollutants and fuel consumption in different passage tolls

\begin{tabular}{ccccccc}
\hline $\begin{array}{c}\text { Congestion } \\
\text { charge (Toman) }\end{array}$ & $\begin{array}{c}\text { Acceptance of } \\
\text { congestion charge }\end{array}$ & $\begin{array}{c}\text { Fuel } \\
\text { consumption }\end{array}$ & $\mathbf{C O}_{\mathbf{2}}$ & $\mathbf{N O}_{\mathbf{x}}$ & $\begin{array}{c}\text { Particulate } \\
\text { Matter }\end{array}$ & $\begin{array}{c}\text { Volatile Organic } \\
\text { Compounds }\end{array}$ \\
\hline 1000 & 64.91 & 49.91 & 56.82 & 49.46 & 36.8 & 63.17 \\
3000 & 45.36 & 31.78 & 37.51 & 30.47 & 19.05 & 43.16 \\
5000 & 31.53 & 20.32 & 24.42 & 18.44 & 9.66 & 28.13 \\
7500 & 13.05 & 8.26 & 9.62 & 7 & 3.16 & 11.61 \\
10000 & 5.47 & 3.57 & 3.98 & 2.85 & 1.22 & 4.86 \\
\hline
\end{tabular}

\section{Summary and Conclusion}

In this study, road pricing effect on traffic flow and traffic pollutants in Shahid Hemmat Highway in Tehran, Iran was investigated. The stated preference (SP) method was employed to find out the reactions of private car users to road pricing. In this regard 219 face-to-face interviews were conducted and entered into the database. Through this study, using designed prices in the scenarios and logit model, the diagram of willingness-to-pay was drawn. To determine how road pricing is related to the traffic flow and pollutants, simulation using Aimsun software was used in the way that both real traffic flow data and the survey results were applied as the simulation software input. Application of survey results in simulation software can give a clearer viewpoint of adopting the policy of pricing, which has not been seen in the other studies. The results of this paper can be applicable for transportation and urban planners in order to overcome both traffic congestion and air pollution problems.

The most important results obtained from this study were as follows:

- People with more expensive cars were more willing to pay and use their own cars and also people with shopping and business purposes were more willing to pay.

- With the increase in the number of car occupants and travel time, the willingness-to-pay was enhanced. The increase in the number of times people used the highway during the month led to the reduction of willingness-to-pay.

- The most significant effect was related to toll such that with the increase in it, the willingness-to-pay was decreased dramatically.

- At the price of TN1000, the contribution of toll acceptance is equal to 64.91 percent. The fuel consumption rate at this price decreases to $49.91 \%$ and the emission rate of $\mathrm{CO}_{2}, \mathrm{NOx}$, particulate matter (PM) and volatile organic compounds (VOCs) pollutants decrease to $56.82 \%, 49.46 \%, 36.8 \%$ and $63.17 \%$, respectively.

- At the highest price -TN10000-, toll acceptability, fuel consumption, $\mathrm{CO}_{2}, \mathrm{NOx}, \mathrm{PM}$ and VOC emission rates decrease to $5.47 \%, 3.57 \%, 3.98 \%, 2.85 \%, 1.22 \%$ and $4.86 \%$, respectively.

- The highest difference in the pollutant emission, relative to the decrease in the number of private cars, occurred at the price of TN3000. In other words, the highest efficiency is at the price of TN3000. 


\section{References}

[1] Euopean Environment Agency, Annual European Community LRTAP Convention Emission Inventory Report 1990-2006. http://www.eea.europa.eu/publications/technical_report_2008_7.

[2] Li, Zheng, John M. Rose, and David Hensher. "Forecasting petrol demand and assessing the impact of selective strategies to reduce fuel consumption." Transportation Planning and Technology 33, no. 5 (2010): 407-421.

[3] BITRE. "Estimating Urban Traffic and Congestion Cost Trends for Australian Cities." Working Paper 71. Bureau of Transport and Regional Economics, Australian Government (2007).

[4] Schrank, David, Bill Eisele, and Tim Lomax. "TTI's 2012 urban mobility report." Texas A\&M Transportation Institute. The Texas A\&M University System (2012).

[5] Litman, T. Online TDM Encyclopedia. Available from: http:Ilwww.vtpi.org (2013).

[6] Pigou, A. C. "The Economics of Welfare, McMillan, London." (1920).

[7] Goh, Mark. "Congestion management and electronic road pricing in Singapore." Journal of Transport Geography 10, no. 1 (2002): 29-38.

[8] Langmyhr, Tore. "Learning from road pricing experience: introducing a second-generation road pricing system." Planning Theory \& Practice 2, no. 1 (2001): 67-80.

[9] Phang, Sock-Yong, and Rex S. Toh. "Road congestion pricing in Singapore: 1975 to 2003." Transportation Journal (2004): 1625.

[10] Jensen-Butler, Chris, Brigitte Sloth, Morten M. Larsen, Bjarne Madsen, and Otto A. Nielsen, eds. Road pricing, the economy and the environment. Springer Science \& Business Media, 2008.

[11] Rotaris, Lucia, Romeo Danielis, Edoardo Marcucci, and Jérôme Massiani. "The urban road pricing scheme to curb pollution in Milan, Italy: Description, impacts and preliminary cost-benefit analysis assessment." Transportation Research Part A: Policy and Practice 44, no. 5 (2010): 359-375.

[12] Transport for London, TfL. "Central London congestion charging: impacts monitoring: Sixth Annual Report." (2008).

[13] Central London congestion scheme consultation with the public and stake holders, Tfl's report to the mayor on the congestion charging scheme variation order consultation, April 2014, tfl.gov.uk/cc.

[14] Eliasson, Jonas. "A cost-benefit analysis of the Stockholm congestion charging system." Transportation Research Part A: Policy and Practice 43, no. 4 (2009): 468-480.

[15] Verhoef, Erik T., Peter Nijkamp, and Piet Rietveld. "The social feasibility of road pricing: a case study for the Randstad area." Journal of Transport Economics and Policy (1997): 255-276.

[16] Schuitema, Geertje, Linda Steg, and Sonja Forward. "Explaining differences in acceptability before and acceptance after the implementation of a congestion charge in Stockholm." Transportation Research Part A: Policy and Practice 44, no. 2 (2010): 99109.

[17] Azari, Kian Ahmadi, Sulistyo Arintono, Hussain Hamid, and Riza Atiq OK Rahmat. "Modelling demand under parking and cordon pricing policy." Transport Policy 25 (2013): 1-9.

[18] Azari, Kian Ahmadi, Sulistyo Arintono, Hussain Hamid, and Seyed Rasoul Davoodi. "Evaluation of demand for different trip purposes under various congestion pricing scenarios." Journal of Transport Geography 29 (2013): 43-51.

[19] Yusuf, Juita-Elena Wie, Lenahan O'Connell, and Khairul A. Anuar. "For whom the tunnel be tolled: A four-factor model for explaining willingness-to-pay tolls." Transportation Research Part A: Policy and Practice 59 (2014): 13-21.

[20] Washbrook, Kevin, Wolfgang Haider, and Mark Jaccard. "Estimating commuter mode choice: A discrete choice analysis of the impact of road pricing and parking charges." Transportation 33, no. 6 (2006): 621-639.

[21] Green, Paul E., and Venkatachary Srinivasan. "Conjoint analysis in consumer research: issues and outlook." Journal of consumer research 5, no. 2 (1978): 103-123.

[22] Ortúzar, J.D., Willumsen, L.G. "Modelling Transport", third ed. John Wiley and Sons, Chichester, UK, (1990).

[23] Louviere, Jordan J., David A. Hensher, and Joffre D. Swait. Stated choice methods: analysis and applications. Cambridge University Press, 2000.

[24] McFadden, Daniel. "Modeling the choice of residential location." Transportation Research Record 673 (1978).

[25] TTTO (Tehran traffic and Transportation Organization and Deputy). "Selective statistics for transport and traffic in Tehran.", (2014). 
[26] TTD (Traffic and Transportation Deputy of Tehran Municipality). "Reasons justifying the construction and completion of the West Hemmat Highway.", (2011).

[27] TTTO (Tehran traffic and Transportation Organization and Deputy). "An overview of Tehran Transportation Master Plan.", (2013). 